\title{
Ocorrência de ouro livre em rochas vulcânicas hidrotermalizadas na Bacia de Castro, Paraná: perspectivas para novas áreas potenciais
}

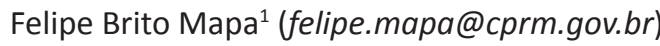 \\ Ivan Pereira Marques ${ }^{1}$ (ivan.marques@cprm.gov.br) \\ Bruno Boito Turra ${ }^{1}$ (bruno.turra@cprm.gov.br) \\ Fabrizio Prior Caltabeloti ${ }^{1}$ (fabrizio.caltabeloti@cprm.gov.br) \\ Luis Carlos Melo Palmeiraํ (luis.palmeira@cprm.gov.br) \\ Rafael Ribeiro Severino ${ }^{1}$ (rafael.severino@cprm.gov.br) \\ Francisco Ferreira de Campos $^{1}$ (francisco.campos@cprm.gov.br) \\ Anderson Dourado Rodrigues da Silva1 (anderson.rodrigues@cprm.gov.br) \\ Felipe Mattos Tavares² (felipe.tavares@cprm.gov.br)
}

${ }^{1}$ CPRM - Serviço Geológico do Brasil, SUREG-SP - Superintendência Regional de São Paulo ${ }^{2}$ CPRM - Serviço Geológico do Brasil, Divisão de Geologia Econômica - Rio de Janeiro

\begin{abstract}
New occurrences of free gold were identified during fieldwork in outcrops located in the western part of the Castro Basin, state of Paraná. These are associated with silicified and sulfide-rich zones in hydrothermally-altered volcanic rocks. The aerogeophysical data indicate that the area of the new targets shows high $\mathrm{K}$ and $\mathrm{eU}$ relative to eTh, suggesting intense hydrothermal alteration. The stream sediment geochemistry shows anomalies with up to $60 \mathrm{ppb}$ of Au and whole-rock geochemical results confirm the presence of up to $54 \mathrm{ppb}$ of $\mathrm{Au}$ in rock samples. The data obtained until now are consistent with those observed in mineralized targets previously described in the same basin, in which an epithermal setting was suggested for the origin of the gold mineralization. Ongoing studies of the new occurrences may indicate an increase in the mineral potential of the Castro Basin.
\end{abstract}

Keywords: Castro Basin. Gold. Silicified breccia. Epithermal. Low-sulphidation.

Palavras-chave: Bacia de Castro. Ouro. Brecha silicificada. Epitermal. Baixa-sulfetação.

\section{INTRODUÇÃO}

Na Bacia de Castro, no Paraná (Figura 1), são conhecidas pelo menos duas áreas mineralizadas em ouro: Torre (depósito) e São Daniel (prospecto). Nestes alvos foram descritas mineralizações auríferas em brecha hidráulica silico-ferruginosa na forma de veios, encaixados em rochas vulcânicas e sedimentares hidrotermalizadas. Os veios são compostos pela assembleia de minerais de ganga quartzo-adulária-sericita e ocorrem associados às zonas de alteração hidrotermal (ABREU et al., 2013), semelhantes aos veios descritos em sistemas epitermais tipo low-sulphidation (HEDENQUIST et al., 1996). O depósito do alvo Torre possui reserva total de 4.055.861 tonela- das de minério, com teor médio de $0,43 \mathrm{~g} / \mathrm{t}$, calculada para teor de corte de 0,2 g/t (PIEKARZ, 1999), ou 1,74 t de ouro contido. No alvo São Daniel foram encontrados veios do tipo bonanza com teores de até $42 \mathrm{~g} / \mathrm{t}$ (ABREU et al., 2013). Sillitoe e Hedenquist (2003) sugeriram que veios deste tipo são mais comuns em ambiente extensional com magmatismo bimodal. A bacia de Castro possui contexto similar, conferindo, portanto, ambiente favorável a mineralizações epitermais.

Apesar do potencial para ouro constatado em investigações anteriores na região (SEOANE, 1999), a Bacia de Castro ainda é pouco estudada. Este fato motivou os trabalhos nesta área, através do Projeto ARIM (Área de Relevante Interesse Mineral) Vale do Ribeira. A partir do estudo dos alvos conhecidos, pro- 
curou-se compreender os controles das mineralizações, a fim de estabelecer critérios para investigação de novas áreas com potencial mineral. Desta forma, foram efetuados trabalhos de campo, análises de imagens de sensoriamento remoto, geofísica e geoquímica de sedimento de corrente. No local denominado Domo do lapó foram encontradas novas ocorrências de ouro em zona sulfetada, com ouro livre associado (localização: $24^{\circ} 39^{\prime} 43^{\prime \prime} \mathrm{S} ; 50^{\circ} 08^{\prime} 34^{\prime \prime} \mathrm{W}$ ) e zona de silicificação (localização: 2440'15"S; 5009'01"W). Ambas as ocorrências estão hospedadas em rochas vulcânicas intermediárias a máficas, situadas no oeste da Bacia de Castro (Figura 1b). Ademais, verificou-se que as ocorrências auríferas da bacia (alvos Torre,
São Daniel e Domo do lapó) estão associadas às áreas com rochas intensamente hidrotermalizadas (cloritização, sericitização, argilização, potassificação e silicificação). A caracterização dessas ocorrências, por meio de petrografia, litogeoquímica e geologia isotópica, está em andamento, sendo apresentado neste informe alguns resultados parciais.

\section{CONTEXTO GEOLÓGICO}

A Bacia de Castro está inserida na borda oeste da Faixa Ribeira Meridional, em contato com rochas da Bacia do Paraná. É limitada a leste pela Falha de

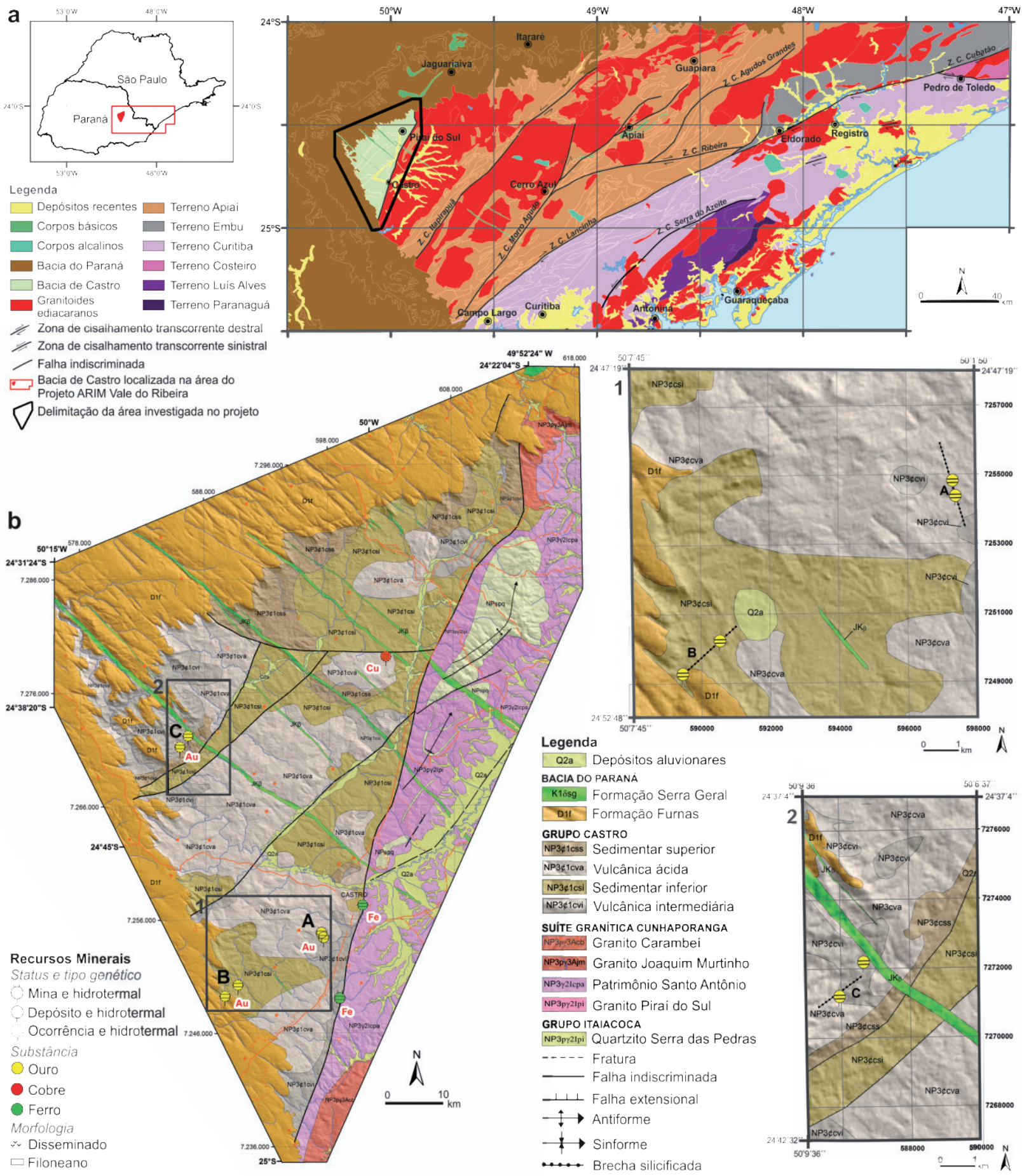

Figura 1 - Mapa tectônico (a) e geológico (b) com a localização das áreas. a) Bacia de Castro situada na área do Projeto ARIM Vale do Ribeira. b) Localização dos alvos detalhados na bacia. 1 - Depósito do Alvo Torre (A) e Alvo São Daniel (B);

2 - Alvo Domo do lapó (C) com as novas ocorrências descritas neste informe. Adaptado de Mapa et al. (2015). 
Castro, um extenso lineamento de direção NNE-SSW com aproximadamente $65 \mathrm{~km}$ de extensão, que separa as unidades do Grupo Castro da Suíte Granítica Cunhaporanga (Figura 1a). O Grupo Castro (TREIN; FUCK, 1967) é composto por uma sequência de rochas vulcanossedimentares de idade ediacarana

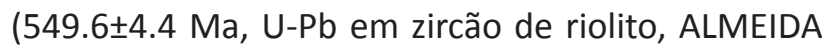
et al., 2010). Moro (1993) subdividiu esse grupo, da base para o topo, em quatro unidades distintas: (I) Unidade Vulcânica Inferior, composta por andesito, riolito, tufo, ignimbrito e conglomerado; (II) Unidade Sedimentar Inferior, constituída por siltito com intercalações de arenito fino e lamito com contribuição vulcânica; (III) Unidade Vulcânica Superior, composta por riolito, ignimbrito quartzo latito, tufo e brecha piroclástica; (IV) Unidade Sedimentar Superior, constituída por conglomerado, arenito conglomerático e arenito arcoseano (Figura 1b).

Soares $(1987,1988)$ afirmou que a Bacia de Castro foi formada em evento transtensional. Almeida et. al. (2010) sugeriu formação por meio de um sistema de bacias tipo rifte, que atuou durante o Ediacarano em todo sudeste da América do Sul. Neste projeto, verificou-se que as unidades que compõem a Bacia de Castro apresentam compartimentação na direção NE-SW, relacionada aos lineamentos verificados nas imagens de satélite e fotografias aéreas e com limites estabelecidos pela aerogeofísica. Essa compartimentação, parcialmente investigada em trabalhos de campo, indica um possível sistema de falhas extensionais que atuou durante o evento gerador da bacia, o que corrobora com a proposta de Almeida et. al. (2010).

\section{DESCRIÇÃO DA OCORRÊNCIA}

A ocorrência do Domo do lapó caracteriza-se por zona de silicificação tabular, em forma de veio, subvertical, de direção ENE-WSW, envolta por zona de argilização. O veio possui 50 metros de comprimento e 10 metros de largura aflorante. É composto essencialmente por quartzo branco de aspecto brechoide, com fraturas preenchidas por óxido de ferro (Figura 2a), e calcedônia cinza com cavidades (Figura $2 b)$. Observa-se também pirolusita dendrítica em cavidades e fraturas. A ocorrência, classificada como brecha hidráulica silicificada, está localizada às margens do rio Piraí-Mirim, próximo à inferida "Falha do Rio Piraí-Mirim". Aproximadamente 1,2 km a nordeste desta ocorrência, às margens deste rio, ocorre zona sulfetada e silicificada, sem estruturação aparente. Essa zona é composta essencialmente por quartzo e pirita de granulação muito fina e estrutura maciça (Figura 2c), na qual se verificou pequenas pintas de ouro livre associado às porções oxidadas da rocha (Figura 2d). Ocorrem também arsenopirita e, possivelmente, cinábrio (HgS - mineral avermelhado). No entanto, a caracterização petrográfica da zona sulfetada ainda não foi concluída. Ambas as ocorrências estão hospedadas em rochas da Unidade Vulcânica Inferior (Figura 1b). Nesta área predomina andesito cinza com textura amigdaloide e estrutura de fluxo magmático, com amígdalas orientadas e preenchidas por celadonita. Tufo cinza, lapili-tufo roxo e brecha piroclástica de cor variegada ocorrem de forma subordinada. Observa-se também que as rochas dessa unidade, próximas à ocorrência, estão afetadas por cloritização pervasiva seletiva.

\section{LITOGEOQUÍMICA}

Foram coletadas seis amostras, sendo duas extraídas das novas ocorrências no alvo Domo do lapó e quatro provenientes dos alvos Torre e São Daniel. As análises para detecção de ouro, platina e paládio foram executadas pelo método fire assay, em rocha total. As análises foram realizadas no laboratório SGS-GEOSOL, com a leitura realizada em ICP-AES (Inductively Coupled Plasma - Atomic Emission Spectrometry). Os resultados (Tabela 1) confirmam a presença de ouro nas ocorrências descritas em campo, nos quais os maiores valores foram detectados em zonas de silicificação nos três alvos (Domo do lapó, Torre e São Daniel). Apesar de os valores obtidos nas amostras da nova ocorrência (Domo do lapó) serem inferiores aos observados nos alvos Torre e São Daniel, e abaixo de 200 ppb, valor considerado anômalo em campanhas de prospecção da DOCEGEO (SEOANE, 1999), estes veios podem estar representando a parte distal de um sistema com maiores concentrações de ouro. O valor obtido na zona argilizada do alvo Torre (Tabela 1) indica que a zona periférica de um possível veio aurífero pode conter pequenas quantidades de ouro. No entanto, ainda não foram realizadas análises sistemáticas das zonas silicificadas e sulfetadas.

\section{DADOS AEROGEOFÍSICOS}

A região de estudo está coberta pelos dados aeromagnetométricos e aerogamaespectrométricos do Projeto Aerogeofísico 1095 Paraná-Santa Catarina (CPRM, 2011). Os dados de magnetometria na área da Bacia de Castro mostram anomalias de direção NW-SE, as quais são relacionadas ao enxame de diques do Arco de Ponta Grossa. Essa resposta dificulta a individualização de outras fontes magnéticas.

A partir dos dados de gamaespectrometria foi gerada a imagem da composição ternária RGB (K, eTh, eU) (Figura 3a). As áreas hidrotermalizadas, destacadas nas imagens, são correlacionadas às porções com tons magenta e vermelho da imagem da composição ternária (Figuras $3 b$ e $3 c$ ), as quais refletem as maiores concentrações de potássio (K) e equivalente urânio (eU), em relação ao equivalente tório (eTh). As imagens do Fator $F$, geradas para as áreas dos alvos (Figuras $3 \mathrm{~d}$ e $3 \mathrm{e}$ ), reforçam essa correlação, indicando quantitativamente as áreas com anomalia de potássio. Deste modo, sugere-se que as regiões com concentrações anômalas de potássio possam ser usadas como vetor prospectivo na delimitação de áreas hidrotermalizadas com possíveis mineralizações auríferas. 

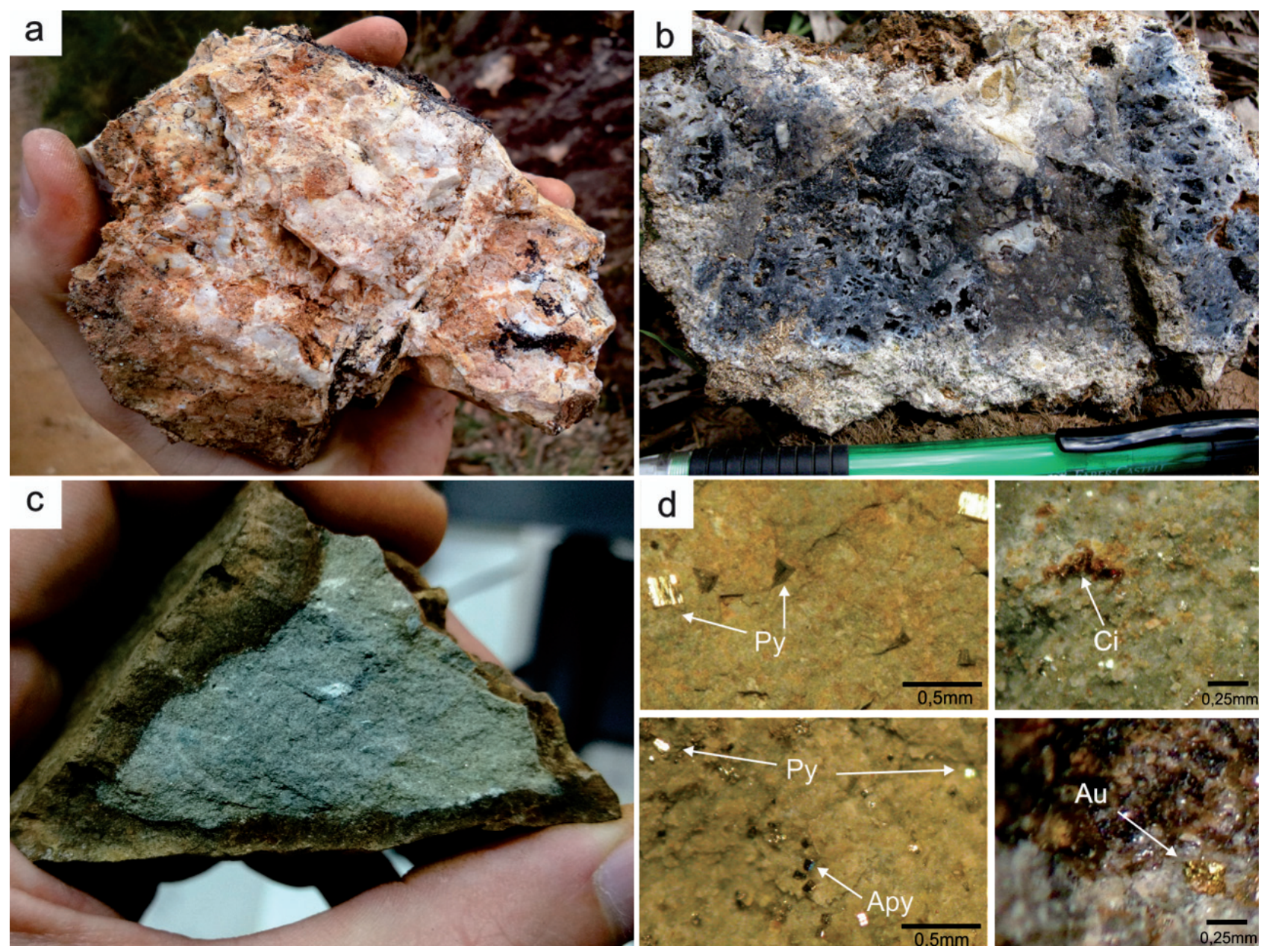

Figura 2 - Detalhe das ocorrências na área do Domo do lapó. a) Brecha hidráulica silicificada, composta por quartzo, com fraturas preenchidas por óxido de ferro; b) Veio de calcedônia cinza, com cavidades; c) Zona sulfetada e silicificada com pirita (Py), arsenopirita (Apy), cinábrio (Ci) e ouro (Au); d) Detalhe da amostra sulfetada em " $\mathrm{C}$ ", com destaque para ocorrência dos sulfetos e de ouro livre, na borda da zona oxidada da amostra.

\section{GEOQUÍMICA DE SUPERFÍCIE}

O projeto contemplou a amostragem de sedimento de corrente em drenagens situadas em toda área da Bacia de Castro. As amostras foram analisadas no laboratório SGS-GEOSOL, em fração menor que 80 mesh, para deteç̧ão de ouro, platina e paládio pelo método fire assay, com a leitura realizada em ICP-AES (Inductively Coupled Plasma Atomic Emission Spectrometry). Foram coletadas e analisadas amostras representativas de 108 bacias de captação, com média de densidade areal igual a 8 $\mathrm{km}^{2}$. Os resultados indicam anomalia para ouro em 20 bacias de captação, com valor entre 6 e 80 ppb. $\mathrm{Na}$ área do alvo São Daniel, conhecidamente mineralizado, a concentração do ouro variou entre $11 \mathrm{e}$ $80 \mathrm{ppb}$ (4 análises em bacias contínuas). $\mathrm{Na}$ área de ocorrência do Domo do lapó, a concentração de ouro variou entre 6 e 60 ppb ( 5 análises em bacias contínuas). O mapa geoquímico do ouro para a Bacia de Castro (Figura 4) mostra que as ocorrências descritas neste informe coincidem com algumas das bacias anômalas para ouro. Vale ressaltar que o valor do background geoquímico na área é inferior a 5 ppb (limite de deteç̧ão do método), observado em $80 \%$ das amostras analisadas.

\section{CONSIDERAÇÕES FINAIS}

O ouro na Bacia de Castro ocorre em brechas hidráulicas silicificadas, em veios tabulares com duas direções principais, NNW-SSE e NNE-SSW, associados a rochas hidrotermalizadas. A presença de corpos mineralizados em diferentes unidades da bacia sugere que o controle litológico/estratigráfico não é preponderante para as mineralizações.

No alvo Torre, o minério de ouro está contido essencialmente em veio de quartzo. Possui estruturação tabular, sub-horizontal a horizontal, de dimensão variável em superfície (entre $10 \mathrm{~m}$ e 200 $\mathrm{m})$. As rochas hospedeiras são afaníticas, de cor branca, com cavidades vazias ou preenchidas com quartzo de dimensões entre 1 e $2 \mathrm{~mm}$ (PIEKARZ, 1999). Durante os trabalhos de campo foi observado que esse horizonte descrito pelo autor ocorre em zona de silicificação de direção NNW-SSE, com extensão de 1,5 km de comprimento, composta por veios de quartzo com aspecto brechado, venular e stockwork. Os veios que cortam a zona de argilização avançada apresentam crescimento sintaxial típico de formação em regime extensional. A zona argilizada tem estrutura maciça e é composta predominantemente por caulim e sericita, formando 
um halo de alteração que envelopa o veio principal mineralizado. Essa zona é interpretada como produto da intensa alteração hidrotermal pervasiva (argilização) e fissural (silicificação), que provavelmente atuou em evento sinvulcânico. Porém, investigações mais acuradas são necessárias para confirmação desta hipótese.

O minério nos alvos Torre e São Daniel são interpretados aqui como brecha hidráulica silicosa, o que também é sugerido para as novas ocorrências do alvo Domo do lapó. Tanto neste alvo como no alvo São Daniel, a direção principal do veio mineralizado é NE-SW, sendo que nas novas ocorrências o ouro está hospedado na Unidade Vulcânica Inferior, enquanto que no alvo São Daniel o minério ocorre encaixado em siltitos da Unidade Sedimentar Inferior. No alvo Torre, a direção principal da mineralização é NNW-SSE, e o minério ocorre em rochas vulcânicas ácidas da Unidade Vulcânica Superior (Figura 1b).

A presença de zonas silicificadas com calcedônia, calcita e sericita e zonas sulfetadas com pirita, arsenopirita, cinábrio e ouro livre, assembleia comum em depósitos epitermais low-sulphidation, reforçam o modelo metalogenético anteriormente sugerido para a bacia. Apesar das análises químicas no alvo Domo do lapó apresentarem baixos teores de ouro nas rochas, a presença de zonas sulfetadas com ouro livre pode estar relacionada à zona periférica de um possível depósito com maior teor. A ocorrência de zonas de bonanza descritas em outras áreas amplia o

Tabela 1 - Resultados de análises químicas por fire assay das ocorrências auríferas.

\begin{tabular}{|c|c|c|c|c|c|c|c|}
\hline Amostra & Ocorrência & Zona de Alteração & Latitude & Longitude & Au (ppb) & Pd (ppb) & Pt (ppb) \\
\hline ICO-194 & Torre & Silicificação & $-24,818356$ & $-50,037588$ & 609 & $<5$ & $<5$ \\
\hline ICO-197 & Torre & Argilização & $-24,822106$ & $-50,035847$ & 14 & $<5$ & $<5$ \\
\hline ICO-211 & São Daniel & Silicificação & $-24,868931$ & $-50,114289$ & 1030 & $<5$ & $<5$ \\
\hline ICO-210 & São Daniel & Argilização & $-24,871596$ & $-50,089681$ & 10 & $<5$ & $<5$ \\
\hline ICO-205 & Domo do lapó & Silicificação & $-24,670883$ & $-50,150129$ & 54 & $<5$ & $<5$ \\
\hline ICO-552 & Domo do lapó & Sulfetação & $-24,662022$ & $-50,142686$ & 18 & $<5$ & $<5$ \\
\hline
\end{tabular}
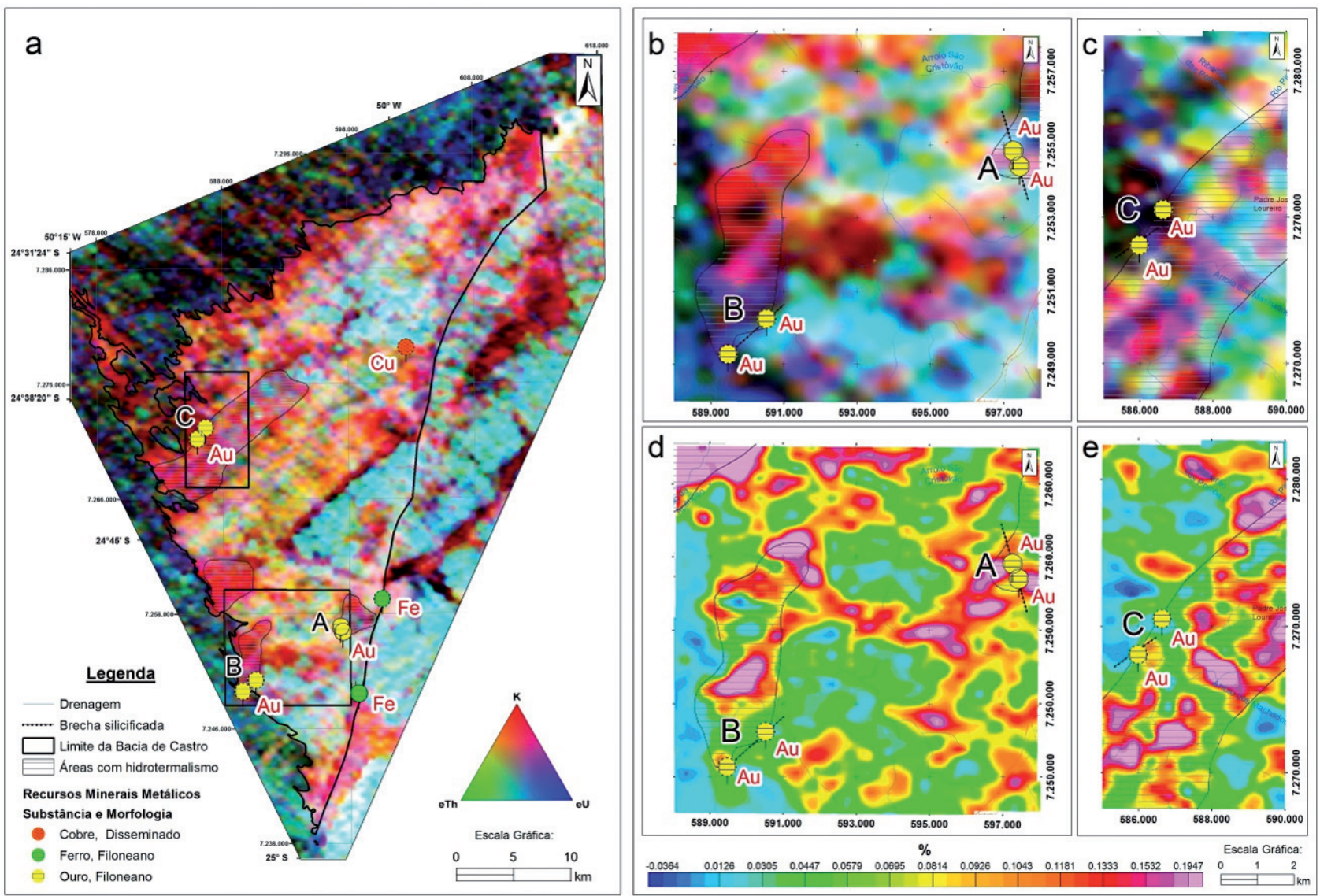

Figura 3 - Mapas gamaespectrométricos da área de estudo com a localização das ocorrências auríferas: depósito do alvo Torre (A), alvo São Daniel (B) e alvo Domo do lapó (C). Imagens da composição ternária RGB (K, eTh, eU) geradas para as áreas da Bacia de Castro (a) e dos alvos Torre e São Daniel (b) e Domo do lapó (c), evidenciando as áreas com maiores concentrações de $\mathrm{K}$ e eU (vermelho e magenta). Imagens do Fator F geradas para as áreas dos alvos Torre e São Daniel

(d) e Domo do lapó (e), mostrando as áreas de maior probabilidade de ocorrência de hidrotermalismo (vermelho e magenta). Os polígonos hachurados são as áreas com rochas intensamente hidrotermalizadas, observadas em campo. 
potencial para novos depósitos de ouro com viabilidade econômica na Bacia de Castro, incluindo a área de ocorrência encontrada.

Os trabalhos no Projeto ARIM Vale do Ribeira ainda estão em andamento. Estão previstas análises petrográficas, geoquímicas e isotópicas, a fim de ca- racterizar a idade, composição e origem dos fluidos mineralizantes. Este estudo metalogenético permitirá melhor entendimento da evolução do sistema mineral na bacia, fornecendo dados mais criteriosos para caracterização do minério e busca de novas áreas potenciais.

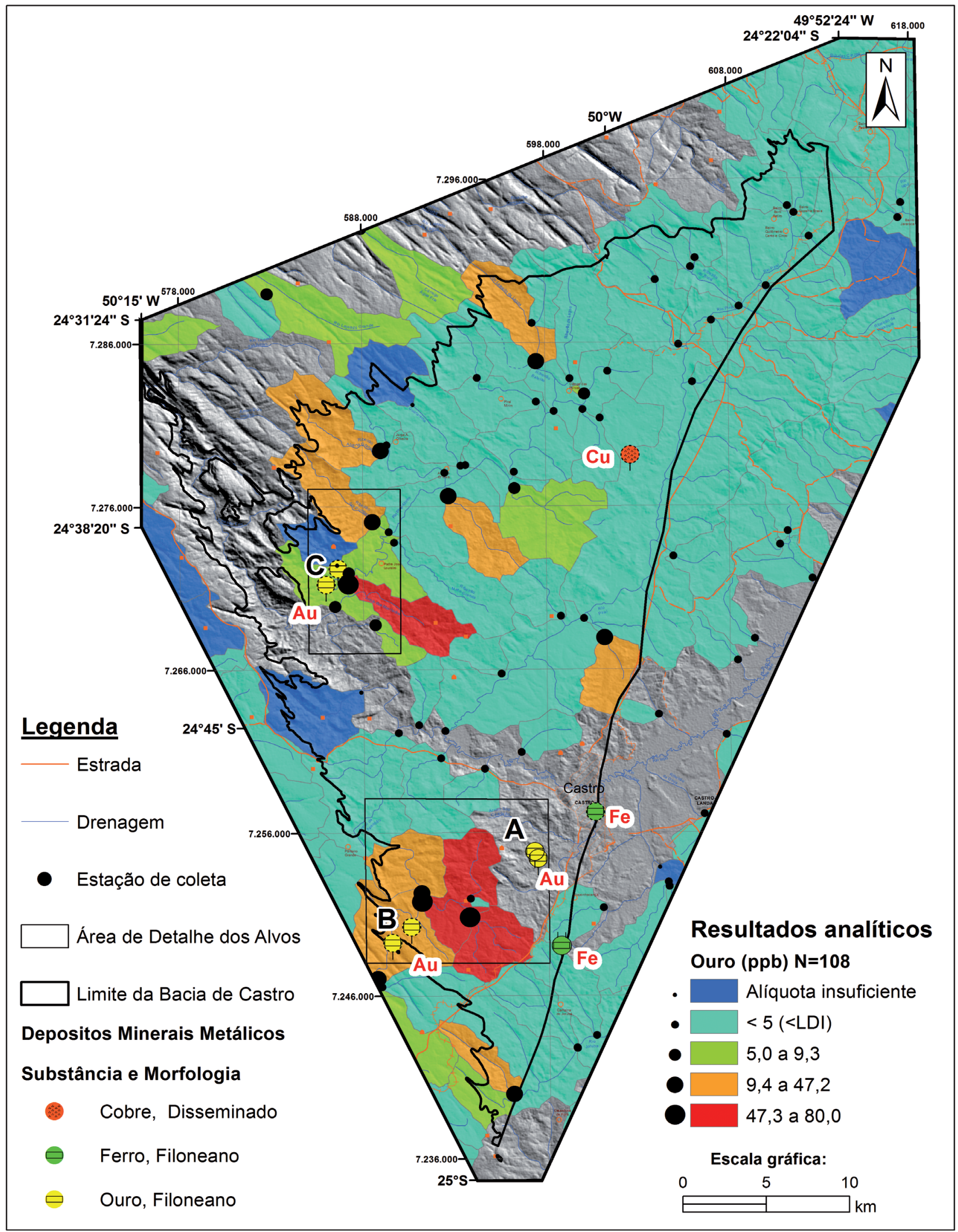

Figura 4 - Mapa geoquímico do ouro em sedimentos de corrente, indicando as bacias anômalas e a localização das ocorrências (A - depósito do alvo Torre; B - alvo São Daniel; C - ocorrência Domo do lapó). Os polígonos de detalhe foram delimitados em função desses resultados geoquímicos e são anômalos em praticamente toda sua área. LDI: limite inferior de detecção. 


\section{REFERÊNCIAS}

ABREU, G. C.; SERRANO, V. D.; MELONI R.E. As mineralizações auríferas epitermais da Bacia de Castro-PR. In: SIMPOSIO BRASILEIRO DE METALOGENIA, 3., 02-05 jun. 2013, Gramado, RS. Anais... Gramado, RS: UFRS, 2013.

ALMEIDA, R. P. A. et al. The ediacaran to cambrian Rift System of Southeastern South America: tectonic implications. Journal of Geology, v. 118, n. 2, p. 145161, mar. 2010.

CPRM - SERVIÇO GEOLÓGICO DO BRASIL. Projeto Aerogeofísico Paraná - Santa Catarina: relatório final do levantamento e processamento dos dados magnetométricos e gamaespectrométricos. Rio de Janeiro: Lasa Prospecções, 2011. 27 v.; il. + mapas. (Programa Geologia do Brasil - PGB)

HEDENQUIST, J. W et al. Epithermal gold deposits: styles, characteristics, and exploration. Resource Geology Special Publication, Tokyo, n. 1, 16 p., 1996.

MAPA, F. B. et al. Áreas de Relevante Interesse Mineral Vale do Ribeira - ARIM: mapa de recursos minerais da Bacia de Castro. São Paulo: CPRM, 2015.1 mapa. Escala 1:100.000.

MORO, R. P. X. A Bacia Ordoviciana do Grupo Castro, PR. 1993, 156 f. Dissertação (Mestrado) - Instituto de Geociência e Ciência Exatas, Universidade Estadual Paulista, Rio Claro, 1993.

PIEKARZ, G. F. Relatório final de pesquisa: processo DNPM 94/826.176. Curitiba: MINEROPAR, 1999.
SEOANE, J. C. S. Geologia do ouro epitermal de Castro, PR: uso de Sistema de Informação Geo-referenciada para avaliação de base de dados geológico-geoquímicos. 1999, 95 f. Tese (Doutorado em Geociências) - Instituto de Geociências, Universidade de Campinas, Campinas, 1999.

SILLITOE, R. H.; HEDENQUIST, J. W. Linkages between volcanotectonic settings, ore-fluid compositions, and epithermal precious metal deposits. In: SIMMONS, S. F.; GRAHAM, I. (Ed.). Economic Volcanic, Geothermal, and Ore-Forming Fluids: Rulers and Witnesses of Processes Within the Earth. Littleton [Colorado-EUA]: Society of Economic Geologists, 2003. p.315 - 343. (Special Publication, 10).

SOARES P.C. Seqüências tecto-sedimentares e tectônica deformadora no centro-oeste do Escudo Paranaense. In: SIMPOSIO SUL-BRASILEIRO DE GEOLOGIA, 3., nov. 1987, Curitiba. Atas... Curitiba: SBG - Núcleos Paraná, Santa Catarina e Rio Grande do Sul, 1987. v. 2, p.743-771.

SOARES, P. C. Tectônica colisional em torno do Bloco Paraná, Brasil. In: CONGRESSO LATINO-AMERICANO DE GEOLOGIA, 7., 1988. Belém (PA). Anais... Belém: SBG - Núcleo Norte, 1988. v.1, p. 63-79.

TREIN, E.; FUCK, R. A. O Grupo Castro. In: BIGARELLA, J. J.; SALAMUNI, R.; PINTO, V. M. (Ed.). Geologia do Pré-Devoniano e intrusivas subsequentes da porção oriental do estado do Paraná. Boletim Paranaense Geociências, Curitiba, v. 23/25, p. 257305, 1967.

\section{INFORME TÉCNICO N 8 \\ Brasilia, agosto de 2016 \\ ISSN: 2448-2242 \\ Publicação on-line seriada \\ CPRM - Serviço Geológico do Brasil. \\ Disponível em: www.cprm.gov.br}

CPRM - Serviço Geológico do Brasil

SBN - Quadra 02 - Bloco H, Ed. Central Brasília, $1^{\circ}$ andar Brasília - DF - Brasil

CEP: 70040-904

Telefone:(61) 2108-8400

www.cprm.gov.br

contatos: seus@cprm.gov.br evandro.klein@cprm.gov.br

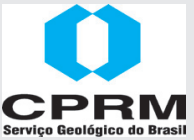

Diretor de Geologia e Recursos Minerais

Roberto Ventura Santos

\section{Corpo Editorial}

Evandro Luiz Klein (Editor)

João Henrique Larizzatti

Luiz Gustavo Rodrigues Pinto

Edilton José dos Santos

\section{Revisores}

Ana Maria Dreher

Fernanda Gonçalves da Cunha

Roberto Gusmão de Oliveira

Evandro Luiz Klein

Normalização Bibliográfica

Nelma Fabrícia da P. Ribeiro Botelho

\section{Editoração Eletrônica}

Marcelo Henrique Borges Leão

Nelma Fabrícia da P. Ribeiro Botelho 